\title{
ANALISIS DAN PERANCANGAN SISTEM APLIKASI COLLABORATIVE AUGMENTED REALITY UNTUK PERANCANGAN TATA LETAK FASILITAS PABRIK
}

\author{
Rini Budiarni \\ Program Studi S1 Informatika \\ Sekolah Tinggi Teknologi Payakumbuh \\ Email: rinibudiarni@gmail.com
}

\begin{abstract}
ABSTRAK
Perancangan tata letak fasilitas pabrik merupakan aktivitas yang sangat vital karena dapat menentukan efisiensi dalam proses produksi dan mempengaruhi berapa lama kelangsungan atau kesuksesan kerja suatu industri. Proses perancangan tata letak fasilitas pabrik ini melibatkan banyak pihak dan dikerjakan secara terpisah. Penggunaan teknologi Augmented Reality (AR) dan beberapa sarana pendukung yang terdapat dalam sebuah aplikasi dapat membantu proses perancangan tata letak pabrik dimana para perancang dapat bekerja bersama-sama (kolaboratif) pada tempat dan waktu yang sama.

Tujuan dari penelitian ini adalah untuk menganalisis, merancang dan mengimplementasikan hasil rancangan ke dalam sebuah prototipe aplikasi Collaborative Augmented Reality for Manufacture Floor Layout and Sceduling (CAR for MFLaSh). Hasil dari pengujian secara fungsionalitas menunjukkan prototipe CAR for MFLaSh dapat mewakili kebutuhan pengguna untuk membantu proses perancangan tata letak fasilitas pabrik yang meliputi perancangan aliran material, perancangan tata letak fasilitas dan alternatif tata letak dengan optimasi biaya penanganan material.
\end{abstract}

Kata kunci: tata letak fasilitas pabrik; kolaboratif; user interface; augmented reality; wxWidgets; CAR for MFLaSh.

\begin{abstract}
The design of manufacture's layout is a vital activity because it can determine the efficiency of the production process. The process of designing the layout of manufacture's facilities involves many parties. The use of Augmented Reality (AR) technology and some of the existing support tools in an application can help the process of designing plant layouts where designers can work together (collaboratively) at the same place and time. The purpose of this study is to analyze, compile and implement the result of manufacture design into an application prototype named Collaborative Augmented Reality for Manufacture Floor Layout and Scheduling (CAR for MFLaSh). CAR for MFLaSh represents the user's need to assist in the layout design process.
\end{abstract}

Keywords: manufacture floor layout; collaborative; user interface; augmented reality, wxWidgets; CAR for MflaSh.

\section{PENDAHULUAN}

Dalam sebuah pabrik, tata letak (layout) fasilitas produksi dan area kerja merupakan elemen dasar yang sangat penting dari kelancaran proses produksi. Tata letak fasilitas pabrik artinya merencanakan: (1) pengalokasian semua mesin, utilitas, pekerja, area customer service, area penyimpanan material, gang, ruang istirahat, ruang makan, dinding internal, kantor dan ruang komputer, (2) pola alur material dan pekerja, ke dalam dan diantara bangunan [1]. Tujuan utama dalam perancangan tata letak fasilitas ini pada dasarnya adalah untuk meminimalkan total biaya yang meliputi biaya konstruksi dan instalasi fasilitas produksi, biaya penanganan bahan (material handling), biaya produksi, biaya perawatan (maintenance costs), biaya keamanan (safety cost) dan biaya penyimpanan produk setengah jadi (inventory in-process costs).

Secara umum penggambaran atau pembentukan layout konvensional dilakukan dalam 4 cara yaitu: (1) digambar dengan cara penggambaran biasa di atas ketas gambar atau kertas kalkir, (2) dibangun dengan model dua dimensi (potongan-potongan, menurut skala menggambarkan bangun dan ukuran tiap peralatan), dipasang di atas atau kisi yang sesuai yang menggambarkan gambaran bangunan, (3) dibangun dengan model berskala tiga dimensi, (4) dibangun dengan kombinasi model berskala dan model dua matra untuk mempermudah reproduksi [2]. Tahapan yang dilalui dalam perancangan tata letak fasilitas pabrik secara 
konvensional ini cukup panjang dan melibatkan banyak pihak. Hal inilah yang menjadi permasalahan yang akan dibahas dalam penelitian ini yaitu bagaimana melakukan analisis dan perancangan untuk membangun sebuah aplikasi yang dapat digunakan untuk membantu proses perancangan tata letak pabrik, dimana dengan menggunakan aplikasi ini semua pihak yang terlibat dapat bekerja bersama (kolaboratif), sehingga proses perancangan tata letak fasilitas pabrik yang tadinya dilakukan secara tertutup menurut pekerjaannya masing-masing, dapat dilakukan secara terbuka dimana pihak-pihak yang terlibat dalam proses perancangan pabrik dapat bekerja secara bersama-sama (kolaboratif) pada waktu dan tempat yang sama dengan menggunakan teknologi AR.

Augmented reality (AR) merupakan sebuah aplikasi yang menampilkan obyek virtual ke dalam dunia nyata, sehingga obyek virtual tersebut seolah-olah tampak di dunia nyata [3]. Lingkungan kolaboratif AR dapat dihasilkan oleh lima hal, yaitu : (1) virtuality dimana obyek yang tidak ada di dunia nyata dapat dilihat dan diuji/diperiksa, (2) augmentation dimana obyek nyata dapat ditambahkan dengan keterangan (annotations) virtual, (3) cooperation dimana pengguna yang banyak (multipleusers) dapat saling melihat dan bekerja secara yang alami (natural), (4) independence dimana setiap pengguna mengontrol/mengatur sudut pandang mereka secara independent, (5) individuality dimana data yang ditampilkan dapat berbeda berdasarkan setiap sudut pandang [4].

Beberapa aplikasi AR yang digunakan sebagai alat bantu perancangan yang sudah dikembangkan antara lain FingARtips yaitu aplikasi interaksi AR dengan menggunakan tangan virtual dalam perancangan pembangunan suatu wilayah perkotaan [5], ARTHUR yaitu aplikasi kolaborasi AR untuk perancangan arsitektur dan perencanaan kota [6], dan BUILD-IT yang merupakan aplikasi AR yang dapat digunakan secara bersama-sama dalam satu kelompok pada satu meja. BUILD-IT ini dapat digunakan dalam berbagai bidang seperti untuk merancang sistem produksi, perencanaan tata kota, arsitektur dan perancangan interior [7].

Salah satu bagian yang terpenting dalam sebuah aplikasi adalah user interface karena user interface merupakan perantara yang disediakan bagi pengguna (user) sehingga pengguna dapat mengetahui apa yang terjadi pada sistem yang digunakannya [8]. Agar dapat digunakan, sebuah user interface harus menyediakan cara untuk mengakses fungsi-fungsi dan fitur-fitur dari aplikasi yang menggambarkan cara berpikir pengguna tentang tugas-tugas yang sanggup didukung oleh sebuah aplikasi. Untuk memenuhi hal tersebut, sebuah aplikasi tidak hanya menyediakan dukungan untuk aspek-aspek yang dibutuhkan dalam pekerjaan pengguna, tetapi juga harus menyediakan cara agar mereka dapat berinterakasi dengan aplikasi tersebut secara alami dan berdasarkan intuisi [9].

Salah satu bentuk user interface yang banyak digunakan saat ini adalah graphical user interface (GUI). GUI merupakan citra grafis yang ditampilkan di layar komputer yang memungkinkan pengguna untuk mengakses aplikasi perangkat lunak dengan memakai menu dropdown, dialog box, radio button, check box, panel, tabs, toolbar, icon shortcuts dan tool lain [8]. Pengaksesan fungsi tersebut dilakukan dengan menggunakan mouse atau keyboard komputer.

GUI biasanya mempunyai tiga komponen utama, yaitu : windowing system, imaging model, dan application program interface (API). Windowing system membangun window, menu, dan dialog box yang tampak pada layar. Imaging model menetapkan huruf dan grafis yang tampak pada layar. WIMP merupakan produk dari windowing system dan imaging model. Komponen yang terakhir yaitu API yang merupakan alat dimana pengguna menetapkan apa dan bagaimana window dan grafis tersebut tampak dilayar [10].

Perangkat yang digunakan untuk pengembangan graphical user interface (GUI) pada aplikasi CAR for MFLaSh ini adalah wxWidgets. wxWidgets merupakan sebuah perangkat lunak yang dapat digunakan untuk membuat aplikasi desktop atau selular dengan GUI. Library wxWidgets menyediakan class-class dan metoda-metoda yang banyak untuk digunakan dan disesuaikan oleh programmer serta memiliki fitur yang berguna untuk berbagai aspek dalam pengembangan aplikasi [11].

Pemilihan Pemilihan wxWidgets sebagai tool yang digunakan untuk pengembangan GUI pada aplikasi CAR for MFLaSh ini adalah karena : (1) dikembangkan dengan bahasa pemrograman $\mathrm{C}++$ yang sesuai dengan bahasa pemrograman yang digunakan dalam pengembangan aplikasi AR, (2) menyediakan class yang dapat mengakses fungsi-fungsi yang terdapat pada library OpenGL yang digunakan dalam aplikasi AR, (3) menyediakan class untuk mengakses database yang diperlukan dalam aplikasi CAR for MFLaSh, dan (4) menyediakan class yang dapat digunakan untuk mengakses fungsi-fungsi diperlukan pada program GUI secara umum, mulai dari toolbar, notebook, tree control, list control, MDI (Multiple Document Interface), dialog box, event handling dan lain-lain.

Tujuan dari penelitian ini adalah untuk menganalisis dan merancang sebuah sistem yang dapat digunakan untuk membantu perancangan tata letak fasilitas, mengimplementasikan hasil rancangan ke dalam sebuah prototipe aplikasi Collaborative Augmented Reality for Manufacture Floor Layout and Sceduling (CAR or MFLaSh), serta menguji prototipe secara fungsionalitas. 


\section{METODOLOGI PENELITIAN}

Tahapan yang akan dilalui dalam proses perancangan dan pengembangan prototipe aplikasi CAR for MFLaSh adalah sebagai berikut :

a) melakukan analisis terhadap kebutuhan sistem yang dapat mendukung proses perancangan tata letak fasilitas pabrik,

b) membuat perancangan sistem yang dapat mendukung semua subsistem yang ada sesuai dengan kebutuhan proses perancangan tata letak fasilitas,

c) implementasi rancangan dalam bentuk prototipe,

d) menguji prototipe secara fungsionalitas.

\subsection{Analisis Kebutuhan Sistem}

Secara umum sistem yang akan dibuat berfungsi sebagai sebuah aplikasi yang berguna untuk membantu para perancang pabrik dalam proses perancangan tata letak fasilitas pabrik dimana pihak-pihak yang terlibat dalam proses perancangan dapat bekerja secara bersama (kolaboratif) pada tempat dan waktu yang sama. Persyaratan dasar yang harus dipenuhi sistem agar sistem dapat berjalan sebagaimana mestinya antara lain : (1) sistem dapat menjadi lembar kerja bersama yang dapat menerima input secara realtime, (2) sistem dapat menampilkan obyek 3D yang dapat menggambarkan lingkungan yang mendekati penggambaran nyata, (3) sistem yang dibuat dapat menerima, menyimpan dan mengolah data yang berkaitan dengan perancangan tata letak fasilitas sebuah pabrik, dan (4) sistem dapat memenuhi semua kebutuhan fungsional user dalam proses perancangan tata letak fasilitas secara umum.

Adapun tahapan proses perancangan tata letak fasilitas pabrik dalam aplikasi CAR for MFLaSh dapat dilihat pada gambar berikut.

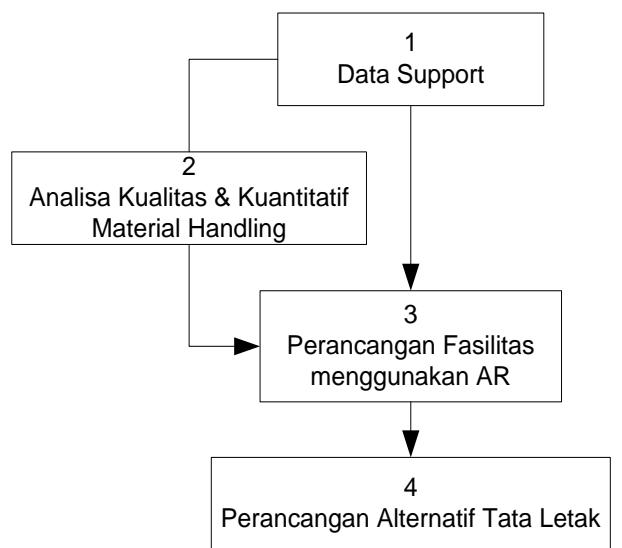

Gambar 1. Prosedur dalam CAR for MFLaSh

Tahap pertama dalam proses perancangan tata letak fasilitas pabrik adalah Data Support, dimana pada tahap ini perancang mengumpulkan dan meng-input data-data yang dibutuhkan dalam proses perancangan, seperti data perusahaan sebagai client, data produk dan data fasilitas. Data yang dimasukkan di tahap ini akan menjadi input bagi tahap dua dan tahap tiga. Tahap kedua adalah tahapan dimana para perancang menenentukan jalur aliran penanganan material (material handling) dengan menggunakan analisa kuantitatif dan kualitatif dimana hasil akhir dari algoritma ini digunakan sebagai rujukan di dalam melakukan perancangan fasilitas menggunakan AR. Selanjutnya, tahap ketiga adalah tahap perancangan tata letak fasilitas pabrik dengan menggunakan teknologi AR, dan terakhir tahap keempat merupakan tahap perancangan alternatif tata letak fasilitas pabrik.

Untuk mendukung proses yang dilalui dalam perancangan tata letak fasilitas pabrik dengan menggunakan CAR for MFLaSh ini, sistem yang dibangun terdiri dari database sebagai tempat penyimpanan data, subsistem workflow untuk perancangan aliran material, subsistem AR untuk perancangan tata letak dengan menggunakan AR, dan subsistem genetic algorithm untuk memberikan alternatif tata letak dan optimasi biayanya dengan menggunakan pengolahan algoritma genetik. 


\subsection{Perancangan Sistem}

Rancangan sistem dari prototipe CAR for MFLaSh ini, dapat dilihat pada gambar berikut:

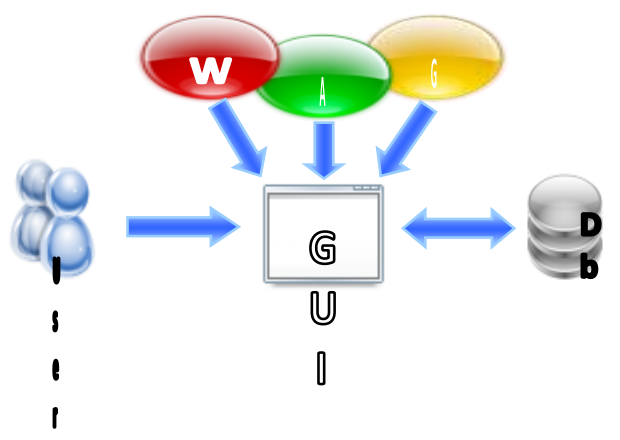

\section{Gambar 2. Rancangan Sistem CAR for MFLaSh}

GUI yang akan dirancang berupa sebuah jendela (window) utama yang melibatkan beberapa komponen antara lain frame, тепи bar, toolbar, work area, panel dan dialog box serta komponen pendukung lainnya. Jendela (window) utama dirancang untuk melakukan interaksi utama sebagai permulaan interaksi dan menetapkan level tertinggi untuk window terikat lainnya. Informasi dan fungsifungsi harus ditampilkan pada pengguna dimana dan kapan mereka membutuhkannya. Pengaturan layout pada layar sebuah window dapat mendorong kecepatan dan keakuratan pemahaman informasi.

Pada jendela (window) utama, terdapat menu-menu yang dapat digunakan perancang dalam proses perancangan tata letak fasilitas pabrik, antara lain : (a) menu Project yang merupakan menu untuk pengelolaan proyek yang akan dilakukan, (b) menu Support Data yang merupakan menu yang dirancang untuk memanggil form pengisian data-data yang berkaitan dengan proyek perancangan tata letak fasilitas pabrik dimana setiap form terkoneksi dengan database, (c) menu View yang merupakan menu yang dirancang untuk mengubah kontent area kerja (work area) dan memanggil beberapa komponen-komponen sistem lainnya, dan (d) menu Help yang merupakan menu yang dirancang untuk memanggil petunjuk penggunaan aplikasi dan keterangan mengenai aplikasi CAR for MFLaSh.

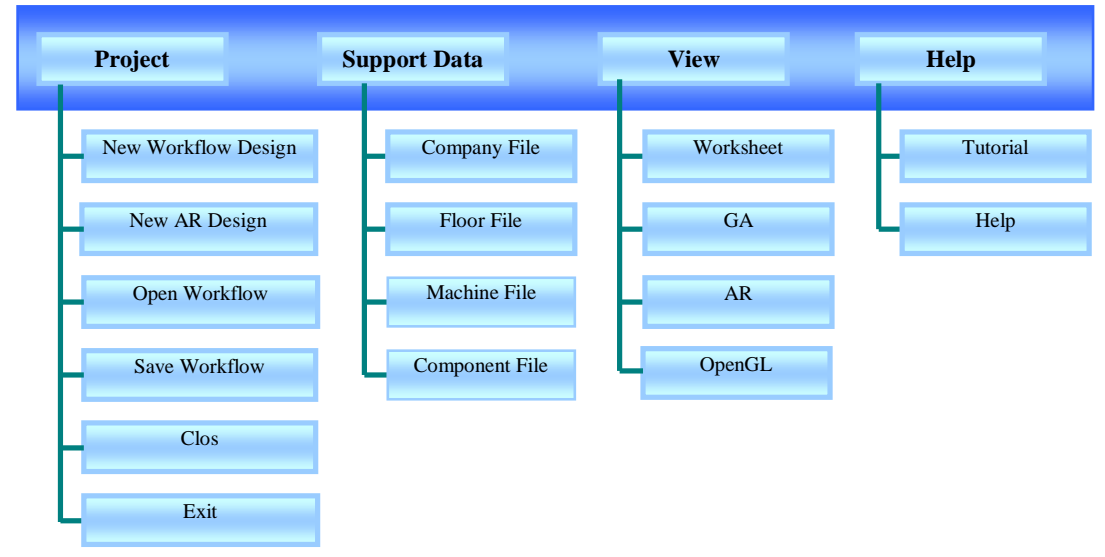

Gambar 3. Rancangan Menu dan Submenu

\section{HASIL DAN PEMBAHASAN}

Berdasarkan analisis kebutuhan dan perancangan sistem yang telah dibuat, diperoleh hasil berupa implementasi dari subsistem-subsistem yang dibutuhkan dalam aplikasi Car for MFLaSh ini.

\subsection{Implementasi GUI}

Implementasi GUI pada prototipe aplikasi ini, dikembangkan dengan menggunakan tool wxWidgets. Pengembangan GUI ini dilakukan dengan menggunakan kelas-kelas yang terdapat pada library wxWidgets. Untuk membangun frame sebagai jendela utama dari aplikasi dengan digunakan fungsi-fungsi yang terdapat pada wxFrame. Hasil dari pengembangan GUI ini berupa sebuah jendela utama dengan beberapa 
komponen yang terdapat didalamnya antara lain, menu, panel lembar kerja dan panel task list. Implementasi dari perancangan GUI dapat dilihat pada gambar berikut:

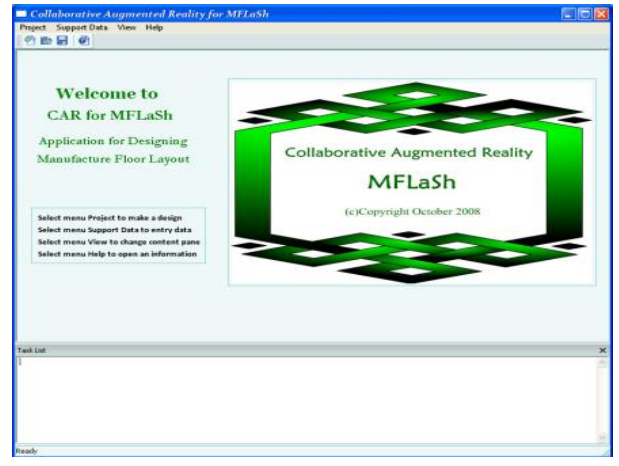

Gambar 4. Window Utama Aplikasi

\subsection{Implementasi Koneksi ke Database}

Database dirancang dengan menggunakan Microsoft Access 2003 dan untuk koneksinya digunakan fungsi-fungsi yang terdapat pada kelas wxDb, wxDbConnectInf dan wxDbTable. Selain itu, untuk memfasilitasi pengguna dalam pengisian database disediakan form yang dirancang dengan menggunakan dialog box. Untuk membuka form pengisian data, pengguna memilih salah satu submenu yang terdapat pada menu Support Data yang menunjukan nama data yang akan diisi. Pengguna memasukkan data melalui text control yang tersedia dan menekan tombol Save untuk menyimpan data. Pengguna juga dapat menambah dan mengubah data yang telah disimpan sebelum form pengisian data ditutup. Koneksi ke database secara langsung terjadi pada saat form pengisian data ditampilkan, ini dapat dilihat pada pesan yang terdapat pada panel Task List di bagian bawah window. Implementasi dari perancangan form pengisian data dan koneksi ke database dapat dilihat pada Gambar 5.

\subsection{Implementasi Penggabungan Subsistem Workflow}

Implementasi subsistem workflow ini dilakukan dengan menggunakan kelas FlowCanvas. Kelas ini berfungsi untuk menampilkan lembar kerja pada jendela utama dan mempunyai fungsi-fungsi yang terdapat pada kelas wxSFDiagramManager yang dapat digunakan untuk merancang aliran material. Untuk menampilkan lembar kerja, pengguna memilih sub menu New Workflow Design yang terdapat dalam menu Project. Pengguna dapat melakukan perancangan aliran material dengan memilih icon-icon yang terdapat pada toolbar dan meletakkannya pada lembar kerja yang telah disediakan. Selain untuk merancang aliran material pengguna juga dapat membuat perancangan tata letak pabrik 2D dengan menggunakan icon-icon yang tersedia pada toolbar. Implementasi dari rancangan penggabungan subsistem workflow ini dapat dilihat pada Gambar 6.

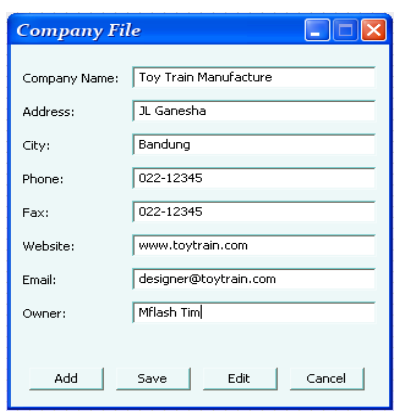

(a)

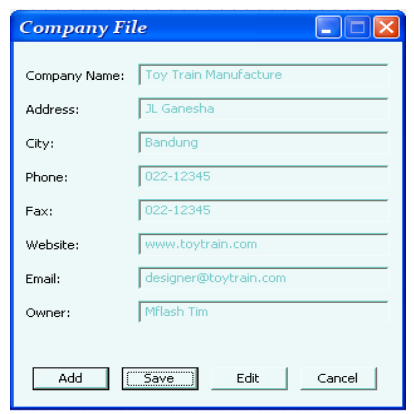

(b)

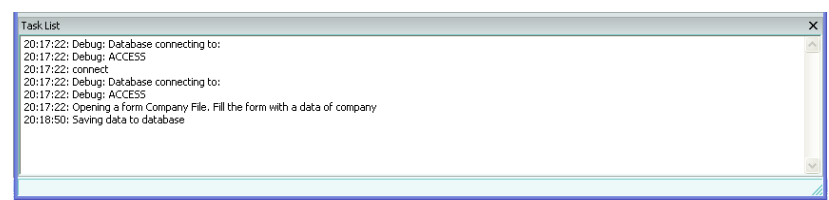

(c)

Gambar 5. Tampilan Form Isian Data 


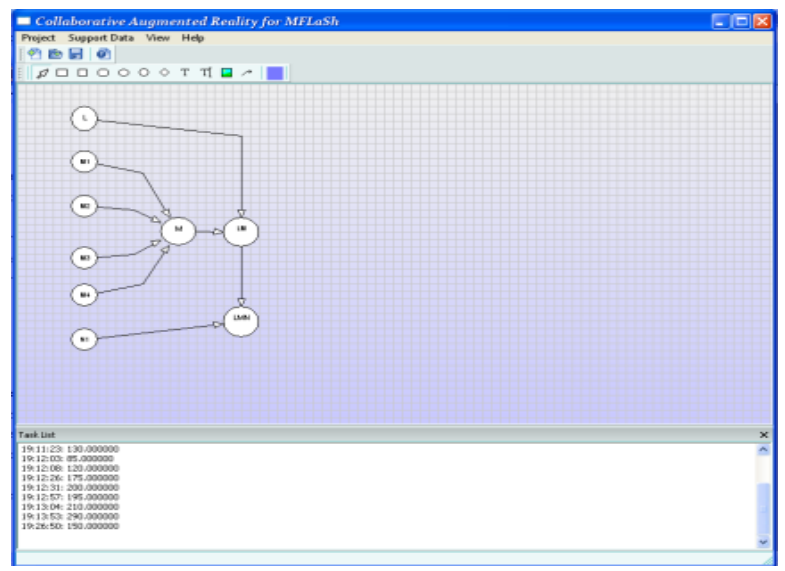

Gambar 6. Tampilan Subsistem Workflow

\subsection{Implementasi Penggabungan Subsistem AR}

Untuk implementasi subsistem AR dilakukan dengan menggunakan fungsi-fungsi yang terdapat pada kelas wxGLCanvas. Kelas ini merupakan kelas yang terdapat pada library wxWidgets yang digunakan untuk memanggil fungsi-fungsi OpenGL yang digunakan dalam pengembangan subsistem AR. Selain itu juga digunakan kelas ARCamera untuk inisialisasi fungsi kamera yang diperlukan untuk subsistem AR. Untuk membuka panel AR, pengguna memilih submenu AR Design yang terdapat dalam menu Project pada menu bar. Selain membuka panel AR, pada window utama juga ditampilkan sebuah panel untuk melihat hasil manipulasi obyek virtual yang dilakukan oleh pengguna. Interaksi pada subsistem AR ini dilakukan dengan menggunakan paddle. Implementasi penggabungan subsistem AR ini dapat dilihat pada Gambar 7.

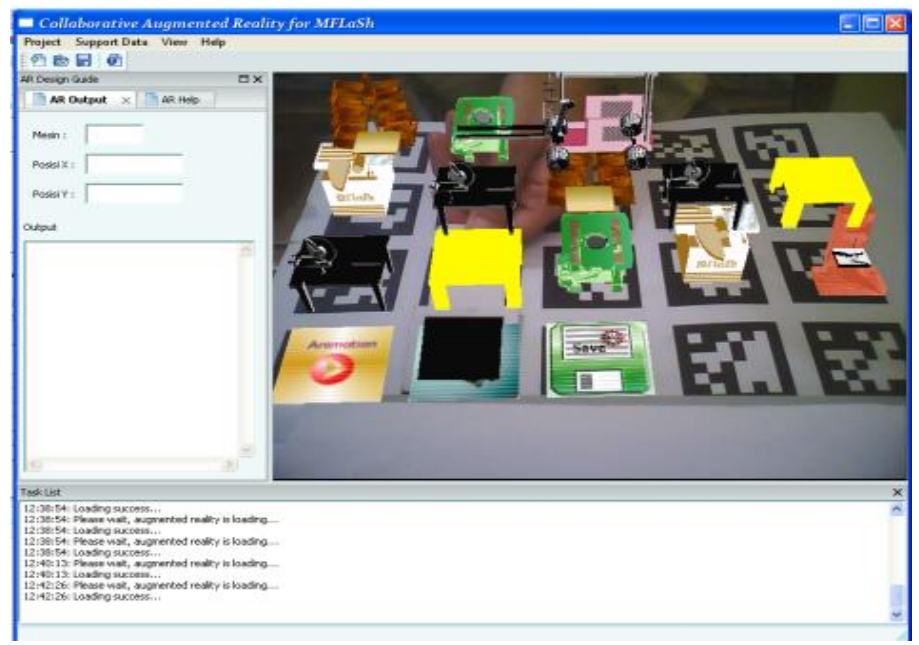

Gambar 7. Tampilan Subsistem AR

\subsection{Implementasi Penggabungan Subsistem GA}

Fungsi-fungsi yang digunakan dalam subsistem GA diletakkan pada kelas MyFrame. Kelas MyFrame juga menyediakan fungsi untuk inisialisasi panel yang dibutuhkan untuk subsistem GA. Untuk membuka panel ini, pengguna memilih submenu Genetic Algorithm yang terdapat dalam menu View pada menubar. Untuk melihat hasil perhitungan GA, pengguna memasukkan data jumlah iterasi yang iinginkan kemudian menekan tombol Run. Hasil perhitungan dapat dilihat pada text control yang telah disediakan. Apabila pengguna ingin mengulangi perhitungan, pengguna dapat menekan tombol Reset untuk menghapus hasil perhitungan. Implementasi penggabungan subsistem GA ini, dapat dilihat pada Gambar 8. 


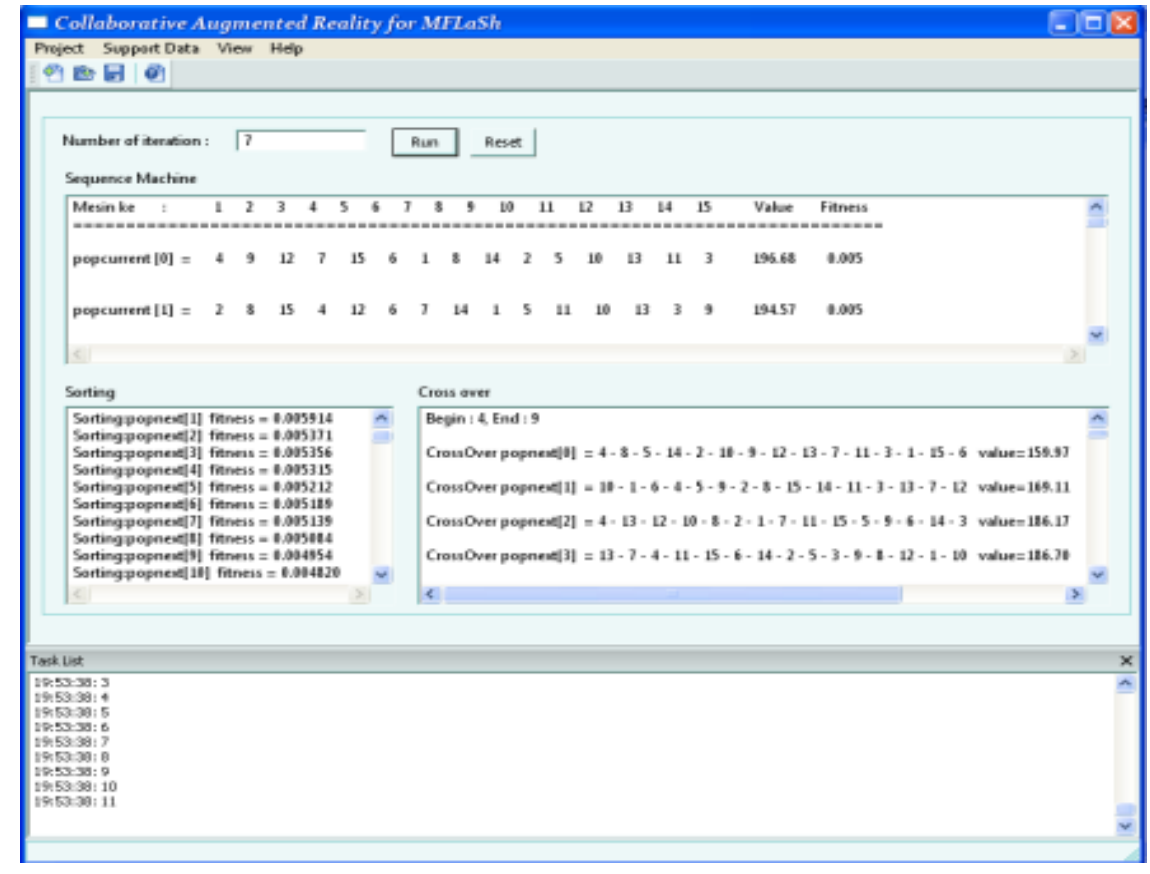

Gambar 8. Tampilan Subsistem GA

\subsection{Pengujian}

Pengujian yang dilakukan adalah pengujian fungsionalitas dari rancangan yang telah diimplementasikan. Dari pengujian fungsionalitas terhadap kinerja aplikasi CAR for MFLaSh yang telah dilakukan, diperoleh hasil evaluasi terhadap kemampuan rancangan dan implementasi sebagai berikut :

a) sistem mampu mendukung proses login para pengguna,

b) secara umum, sistem dapat terhubung dengan semua subsistem yang terdapat pada aplikasi,

c) sistem dapat terhubung dengan database dan dapat menyimpan, menambah, dan mengubah data,

d) sistem dapat menampilkan panel-panel yang berhubungan dengan subsistem yang ada pada aplikasi yaitu panel untuk subsistem workflow; panel untuk subsistem AR; dan panel untuk subsistem GA,

e) sistem dapat menampilkan hasil tangkapan kamera pada panel AR, dan menampilkan semua obyek virtual,

f) sistem dapat menampilkan hasil pengolahan algoritma genetik. berikut :

Adapun kelemahan-kelemahan pada sistem yang ditemukan pada hasil pengujian adalah sebagai

a) fungsi login yang disediakan masih belum terhubung dengan database, fungsi login berjalan dengan melakukan pengecekan apakah pengguna memasukkan password atau tidak,

b) hasil render tekstur pada pada obyek 3D yang terdapat pada subsistem AR masih belum sempurna,

c) interaksi pada subsistem AR yaitu pada saat menyalin obyek 3D ke paddle masih sulit dilakukan,

d) fungsi untuk menyimpan hasil rancangan baik rancangan aliran material maupun rancangan tata letak dengan menggunakan AR yang sudah dimplementasikan belum berhasil dijalankan.

\section{KESIMPULAN}

Kesimpulan yang diperoleh berdasarkan hasil pengujian telah dilakukan adalah prototipe dari aplikasi CAR for MFLaSh ini dapat mewakili kebutuhan pengguna untuk membantu dalam proses perancangan tata letak fasilitas pabrik, diantaranya :

a) dapat menambah, menyimpan dan mengubah data-data yang diperlukan dalam proses perancangan tata letak pabrik pada tahap pengumpulan data.

b) dapat digunakan untuk melakukan perancangan aliran materialdalam proses produksi untuk melihat hubungan antar fasilitas yang terdapat pada lantai produksi.

c) dapat digunakan untuk melihat optimasi biaya produksi yang dilakukan dengan pengolah algoritma genetik. 
d) dapat digunakan untuk merancang tata letak fasilitas pabrik dalam visualisasi 3D dengan menggunakan AR.

\section{DAFTAR PUSTAKA}

[1] Gaither Norman, Frazier Greg.(1999), Production and Operation Management, South-Western College Publishing.

[2] Apple, James, M. 1977. Plant Layout and Material Handling. New York: Jon Willey \& Sons.

[3] Azuma, Ronald. (1997), “A Survey of Augmented Reality”, Presence: Teleoperators and Virtual Environments, 6(4):355-385

[4] Schmalsteig, A, et al. (1996), "Studierstube-An Environment for Collaboration in Augmented Reality”, CVE '96 Workshop Preceedings 19-20 ${ }^{\text {th }}$ September 1996, Nottingham, Great Britain.

[5] Buchman, Volkert and Violich, Stephen and Billinghurst, Mark and Cockburn, Andy. (2004), "FingARtips - Gesture Based Direct Manipulation in Augmented Reality", HitLabNZ, http ://www.hitlabnz.org, 17 Juni 2008, $10: 31$ WIB

[6] Broll, Wolfgang. et. al. (2004), "ARTHUR : A Collaborative Augmented Environment for Architectural Design and Urban Planning”, Journal of Virtual Reality and Brodcasting, Vol. 1 No.1, Fraunhofer Institute for Applied Information Technology (FIT) Sank Augustin, Germany http ://www.jvrb.org/articles/34/ARTHUR2004.pdf, 9 Juni 2008, 12 :16 WIB

[7] Fjeld, M. et.a.l. (1998), "BUILD-IT : an intuitive simulation tool for multi-expert layout processes", Zurich, Switzerland, http ://www.fjeld.ch/pub/media/1998-Fjeld_et_al-\%20BUILDIT_an_Intuitive_Simulation_Tool_for_Multi-expert_Layout_Processes.pdf, 9 Juni 2008, 14 :24 WIB

[8] Febrian, Jack. (2004), Pengetahuan Komputer dan Teknologi Informasi. Bandung: Informatika.

[9] Wood, Larry E., User Interface Design : Bridging the Gap from User Requirements to Design, CRC Press.

[10] Hayes, Frank and Nick, Baran, A Guide to GUIs. http ://www.guidebookgallery.org/articles/aguidetoguis, 16 Februari 2009, 11 :45 WIB.

[11] Smart, Julian, Hock, Kevin and Csomor, Stefan, (2006), Cross-Platform GUI Programming with wxWidgets, USA: Prentice Hall PTR, Pearson Education, Inc. 